\title{
O PODER DE CELEBRAR TRATADOS NO DIREITO POSITIVO
}

\section{BRASILEIRO: A EXPERIÊNCIA PRÁTICA DO BRASIL}

Salomão Almeida Barbosa

\begin{abstract}
RESUMO
O trabalho parte das abordagens a respeito do Direito e Relações Internacionais e de Constituição e Relações Exteriores a partir de considerações de Celso Lafer, Pedro Dallari e de Antonio Remiro Brotons. Analisa a questão a respeito do poder de celebrar tratados no direito positivo brasileiro e a experiência prática do Brasil, tendo por fundamento precípuo a obra "O poder de celebrar tratados: competência dos poderes constituídos para a celebração de tratados, à luz do direito internacional, do direito comparado e do direito constitucional brasileiro" do Prof. Dr. Antônio Paulo Cachapuz de Medeiros; para tanto, é desenvolvido um histórico das Constituições brasileiras de 1824, 1891, 1934, 1937, 1946, 1967 e 1988, bem como discutidas as questões a respeito da terminologia e da competência privativa do Senado Federal, objeto do art. 52, V, em face da competência exclusiva do Congresso Nacional prevista no art. 49, I, da Constituição Federal, da antinomia entre os arts. 49 e 84, VIII, da mesma Carta. São analisadas, ainda, a prática brasileira na celebração de tratados sob o regime da Constituição Federal de 1988, bem como a jurisprudência recente do Supremo Tribunal Federal, acentuando-se a paridade normativa entre atos internacionais e normas infraconstitucionais e o o Pacto de São José da Costa Rica.
\end{abstract}

Palavras-Chaves: Direito Internacional. Direito Constitucional. Direito dos Tratados. Supremo Tribunal Federal. 


\section{INTRODUÇÃO}

\section{DIREITO E RELAÇÕES INTERNACIONAIS}

O ex-chanceler Celso LAFER (apud DALLARI, 1994, p. 2-3) afirma que o Tratado de Westfália, de 1648, “representou a consolidação de uma ordem mundial constituída exclusivamente pelos governos de estados soberanos. Estes teriam liberdade absoluta para governar um espaço nacional - podendo entrar em acordos voluntários tratados - para regular as relações externas e intraconexões de variados tipos”. Assim, a Lógica de Westfália, para Celso LAFER, traduz governos soberanos e iguais, vale dizer, o equilíbrio mecânico do poder está baseado na ação individual dos Estados, únicos atores da ação política, o que nos remete ao fundamento precípuo do Direito Internacional Clássico: sistema de normas de mútua abstenção (cf. DALLARI, 1994, p. 2-3).

Todavia, acentua o ex-chanceler a denominada corrosão dos paradigmas da Lógica de Wesfália, motivada, precipuamente, pela tensão entre a igualdade na teoria e a desigualdade de fato, o que se aprofunda, ainda mais, em razão de dois fenômenos que abalam o conceito tradicional de soberania: a necessidade da cooperação intergovernamental e o transnacionalismo, aqui entendido como aquele conjunto de relações que não transitam necessariamente pelos canais diplomáticos do Estado, mas que têm o poder de influir nas sociedades (cf. LAFER, 1982, p. 71-83).

\section{CONSTITUIÇÃO E RELAÇÕES EXTERIORES}

Registra ainda o Prof. Celso LAFER (apud DALLARI, 1994, p. 12-13) que “a teoria política, desde Kant, vê uma associação positiva entre a democracia no plano interno, e um internacionalismo de vocação pacífica, guiado pelos princípios de coexistência e cooperação com os demais membros da sociedade internacional”. A análise da disciplina constitucional e jurídica do desenvolvimento das relações exteriores não deve prescindir, consoante o Prof. Pedro DALLARI, das lições de Antonio Remiro BROTONS (1984, p. 13), o qual, fundado em importantes teóricos da organização democrática do exercício do

poder político (Locke, Rousseau e Tocqueville), diz que há uma tendência considerável de que os assuntos inerentes às relações exteriores, em face de suas características intrínsecas, 
são próprios da alçada de governo, entendido enquanto Poder Executivo, e não do Parlamento ou do conjunto da população. Para tanto, BROTONS faz a distinção entre função de Estado, na qual há uma identificação dos interesses nacionais essenciais ou vitais, caracterizados por valores quase permanentes, e função de governo, em que a realização, individualização e execução de interesses secundários podem ser pactuados sem menosprezo das referidas funções de Estado (cf. BROTONS, 1984, p. 17). Aliás, ao tratar da publicidade dos atos atinentes às relações exteriores do Estado, noticia Celso LAFER que a diplomacia na Idade Moderna era atividade sigilosa; o segredo era instrumento normal do exercício do poder do príncipe (ex parte principis), daí a teoria da razão de Estado que permitia ao soberano estar acima do direito comum no interesse do bem público, com fundamento no jus dominationis (cf. LAFER, 1989, p. 36-46).

A distinção de BROTONS tem o condão de ressaltar, como contraponto da perspectiva administrativista, a institucionalização, mormente pela via constitucional, de paradigmas e regras de procedimento que possibilitem o balizamento e o acompanhamento da política externa governamental por parte da sociedade. Neste contexto, a constitucionalização de princípios das relações exteriores viabiliza o controle político da ação externa do Estado pelo Poder Legislativo e o controle jurídico pelo Poder Judiciário (cf. BROTONS, 1984, p. 93103).

2. O PODER DE CELEBRAR TRATADOS NO DIREITO POSITIVO BRASILEIRO. A PRÁTICA BRASILEIRA E EXEMPLOS: A OBRA “O PODER DE CELEBRAR TRATADOS: COMPETÊNCIA DOS PODERES CONSTITUÍDOS PARA A CELEBRAÇÃO DE TRATADOS, À LUZ DO DIREITO INTERNACIONAL, DO DIREITO COMPARADO E DO DIREITO CONSTITUCIONAL BRASILEIRO”, DO PROF. DR. ANTÔNIO PAULO CACHAPUZ DE MEDEIROS (MEDEIROS, 1995)

O tema objeto do presente trabalho não pode nem deve prescindir da excelente obra em epígrafe, do atual Consultor Jurídico do Ministério das Relações Exteriores, Prof. Dr. Antônio Paulo Cachapuz de MEDEIROS, fruto de sua tese de doutorado, aprovada com distinção e louvor na Universidade de São Paulo em 1995. Aliás, o Prof. Dr. Luiz Olavo BAPTISTA, prefaciando citada obra, diz que ela "se tornará leitura obrigatória dos estudiosos do direito internacional, assim como do constitucional, e que não pode deixar de integrar as bibliotecas jurídicas bem compostas” (MEDEIROS, 1995, prefácio). 
Sobre o assunto em tela, o Prof. Cachapuz de MEDEIROS desenvolve, na citada obra, importante histórico das Constituições brasileiras (cf. MEDEIROS, 1995).

\subsection{A CONSTITUIÇÃO DE 1824}

Noticia o Prof. Cachapuz de MEDEIROS que a Constituição de 1824 repetiu, no que concerne à celebração dos tratados, os termos do Projeto do Conselho de Estado nomeado por D. Pedro I, sendo ainda certo que a aprovação pelo Legislativo somente ocorreria para os tratados concluídos em tempo de paz que envolvessem cessão ou troca de território do Império ou de suas possessões (art. 102, $7^{\circ}$ e $8^{\circ}$ ) (cf. MEDEIROS, 1995, p. 8090).

Tem o seguinte teor o art. 102, $7^{\circ}$ e $8^{\circ}$, da Constituição de 1824 :

“Art. 102. O Imperador é o Chefe do Poder Executivo, e o exercita pelos seus Ministros de Estado. Suas principais atribuições são:

(...)

$7^{\circ}$. Dirigir as negociações políticas com as Nações Estrangeiras.

$8^{\circ}$. Fazer tratados de aliança ofensiva e defensiva, de subsídio e comércio, levando-os, depois de concluídos ao conhecimento da Assembléia Geral, quando o interesse e segurança do Estado o permitirem. Se os tratados concluídos em tempo de paz envolverem cessão ou troca de território do Império, ou de possessões a que o Império tenha direito, não serão ratificados sem terem sido aprovados pela Assembléia Geral.”

Houve reação do Parlamento ao sistema de tratados no Governo de D. Pedro I, sistema esse formado por acordos celebrados com potências estrangeiras que acarretavam desvantagens globais e específicas para o Brasil. Neste contexto - movimento reformista da Constituição de 1824 - menciona o Prof. Cachapuz de MEDEIROS, entre outros, os projetos conhecidos como “Constituição de Pouso Alegre” (1833) e “Constituição da República Rio-Grandense” (1843, fruto de assembléia constituinte reunida na cidade de Alegrete-RS durante a Revolução Farroupilha) (cf. MEDEIROS, 1995, p. 94-96). 


\subsection{A CONSTITUIÇÃO DE 1891}

Dispõem os arts. 34 e 48 da primeira Constituição republicana brasileira, in verbis

“Art. 34. Compete privativamente ao Congresso Nacional:

(...)

12. Resolver definitivamente sobre os tratados e convenções com as nações estrangeiras.

Art. 48. Compete privativamente ao Presidente da República:

(...)

16. Entabular negociações internacionais, celebrar ajustes, convenções e tratados, sempre ad referendum do Congresso, e aprovar os que os Estados celebrarem na conformidade do artigo 65, submetendo-os, quando cumprir, à autoridade do Congresso."

Consoante lição de Afonso Arinos de Melo FRANCO, são equivalentes as expressões resolver definitivamente, mantida até hoje na Constituição brasileira, e ad referendum (cf. FRANCO, 1957, p. 263). Todavia, informa o Prof. Cachapuz de MEDEIROS que a expressão resolver definitivamente tem sido considerada inadequada, uma vez que a decisão efetivamente definitiva cabe ao Presidente da República, que poderá ou não ratificar os tratados internacionais (cf. MEDEIROS, 1995, p. 117), sendo certo que, para o ex-chanceler e ex-Ministro do Supremo Tribunal Federal José Francisco REZEK, a aprovação legislativa traduz simplesmente ausência de oposição ao tratado internacional pelo Congresso Nacional, incumbindo ao Chefe de Estado, a partir desse ponto, a decisão verdadeiramente definitiva (cf. REZEK, 1973, p. 110-111).

Ainda sobre o contexto histórico da Constituição republicana de 1891, registra o diplomata João Hermes Pereira de ARAÚJO, que Rui Barbosa, em 19.6.1893, em artigo publicado no Jornal do Brasil, noticiou que a Lei $\mathrm{n}^{0}$ 11, de 30.9.1892, do Estado do Amazonas, “aprovava” o Tratado de Navegação do Rio Javari e seus afluentes celebrado pelo “Governo federal com a República do Peru” em 10.10.1891. É bem provável que este seja o primeiro exemplo da denominada paradiplomacia na história constitucional republicana brasileira (cf. ARAÚJO, 1958, p. 330). 
Finalmente, João Hermes P. de ARAÚJO (1958, p. 333-334) também destaca que "nossa vida internacional republicana" teve início com a rejeição pelo Congresso Nacional, em 10.8.1891, do Tratado de Montevidéu, que procurou resolver o litígio das Missões.

\subsection{AS CONSTITUIÇÕES DE 1934 E 1967: PANORAMA GERAL}

\section{Constituição de 1934}

“Art. 40. É da competência exclusiva do Poder Legislativo:

a) resolver definitivamente sobre tratados e convenções com as nações estrangeiras, celebrados pelo Presidente da República, inclusive os relativos à paz;

(...)

Art. 56. Compete privativamente ao Presidente da República:

(...)

$6^{\circ}$. Celebrar convenções e tratados internacionais, ad referendum do Poder Legislativo;”

Constituição de 1937

“Art. 54. Terá início no Conselho Federal a discussão e votação dos projetos de lei sobre:

a) tratados e convenções internacionais;

\section{(...)}

Art. 74. Compete privativamente ao Presidente da República:

(...)

d) celebrar convenções e tratados internacionais ad referendum do Poder Legislativo;”

Constituição de 1946

“Art. 66. É da competência exclusiva do Congresso Nacional:

1 - resolver definitivamente sobre os tratados e convenções celebradas com os Estados estrangeiros pelo Presidente da República;

(...)

Art. 87. Compete privativamente ao Presidente da República:

(...) 
VII - celebrar tratados e convenções internacionais ad referendum do Congresso Nacional;”

Constituição de 1967, com a redação da EC nº 1/69

“Art. 44 - É da competência exclusiva do Congresso Nacional:

I - resolver definitivamente sobre os tratados, convenções e atos internacionais celebrados pelo Presidente da República;

(...)

Art. 81. Compete privativamente ao Presidente da República:

(...)

$\mathrm{X}$ - celebrar tratados, convenções e atos internacionais, ad referendum do Congresso Nacional;"

Assevera o Dr. Cachapuz de MEDEIROS que o Governo brasileiro manteve a prática de celebração de acordos em forma simplificada, vale dizer, com mitigação da compulsoriedade da deliberação do Legislativo sobre todos os atos internacionais, considerando a prática interna e internacional. É destacado, ainda, que a expressão “compete privativamente ao Congresso Nacional”, contida no texto constitucional de 1891, fora substituída, nas constituições subseqüentes, pela expressão "competência exclusiva” (do Congresso Nacional) (cf. MEDEIROS, 1995, p. 313). Para tanto, reporta-se à lição de Afonso Arinos de Melo FRANCO, quando nos ensina que a competência privativa de um poder não afasta a colaboração do outro na realização do ato; por sua vez, a competência exclusiva, por si só, afasta aquela contribuição (cf. FRANCO, 1957, p. 262).

Ademais, sobre a tese de que nem todos os acordos internacionais necessitam de aprovação legislativa, é relatada a histórica polêmica entre Hildebrando ACCIOLY e Haroldo VALLADÃO. O Prof. ACCIOLY sustentou que o país pode ser parte em atos internacionais que não dependem da aprovação do Congresso Nacional, ou seja, naqueles que independem de ratificação (cf. ACCIOLY, 1948, p. 11-15). Por sua vez, o Prof. Haroldo VALLADÃO rejeitou a posição de ACCIOLY ao afirmar que todos os tratados necessitam de aprovação legislativa, argumentando, em síntese, que a amplitude maior ou menor dos poderes do Governo de um Estado para celebrar tratados é assunto típico de Direito Interno, que escapa ao Direito Internacional, certo que a Convenção de Havana 
sobre o Direito dos Tratados de 1928, aprovada e ratificada pelo Brasil, exige, sem exceção, a ratificação para todos os tratados (cf. VALLADÃO, 1950, p. 12-95). Acrescenta o Prof. Cachapuz de MEDEIROS que a posição do Itamaraty, forte em Levi CARNEIRO, corrobora a tese de Hildebrando ACCIOLY (cf. MEDEIROS, 1995, p. 296-299).

Importante questão trazida pelo Prof. Cachapuz de MEDEIROS diz respeito à posição, defendida por Guido Fernando da Silva SOARES, no sentido de que há, no Brasil, entendimento implícito entre os Poderes Legislativo e Executivo de que os acordos de implementação de outros mais gerais (traités-cadre ou acordos de referência) podem ser concluídos pelo Executivo, em forma simplificada, se aqueles gerais, que traçaram a moldura normativa, tiverem sido aprovados pelo Legislativo. Esta conclusão foi oriunda do fato de que no dia seguinte à assinatura do Acordo sobre Cooperação no Campo dos Usos Pacíficos de Energia Nuclear entre o Brasil e a República Federal da Alemanha, firmado em Bonn a 27.6.1975, os Ministros das Minas e Energia do Brasil e da Tecnologia da Alemanha assinaram um protocolo para implementação do acordo, sendo certo que, posteriormente, somente o acordo foi submetido e aprovado pelo Congresso Nacional (cf. SOARES, 1977, p. 322). Ainda sobre o assunto, o Juiz da Corte Internacional de Justiça J. Francisco REZEK considera o acordo executivo prática convalidável, desde que fundada na Constituição: acordo executivo como subproduto de tratado vigente ou acordo executivo como expressão de diplomacia ordinária, tais como o modus vivendi e o pactum de contrahendo (cf. REZEK, 1984, p. 306-309).

Ressalte-se, também, que sob a égide das constituições republicanas anteriores a 1988 houve reações do Congresso Nacional contra a celebração de acordos em forma simplificada. Dentre outros, o Prof. Cachapuz de MEDEIROS faz alusão ao acordo Brasil e Itália sobre investimentos, cujo Ajuste de Pagamentos, de 1952, não fora submetido ao Parlamento, o mesmo ocorrendo com o Ajuste de Instalação de Posto de Teleguiados em Fernando de Noronha, ao argumento precípuo de que se tratava de mero ato executivo do Acordo de Assistência Militar entre o Brasil e os Estados Unidos de 1952, já aprovado pelo Congresso Nacional (cf. MEDEIROS, 1995, p. 313-337) 


\subsection{A CONSTITUIÇÃO DE 1988}

A Constituição Federal de 1988, no que concerne ao tema aqui versado, assim dispõe:

“Art. 49 - É da competência exclusiva do Congresso Nacional:

I - resolver definitivamente sobre tratados, acordos ou atos internacionais que acarretem encargos ou compromissos gravosos ao patrimônio nacional;

(...)

Art. 52 - Compete privativamente ao Senado Federal:

(...)

V - autorizar operações externas de natureza financeira, de interesse da União, dos Estados, do Distrito Federal, dos Territórios e dos Municípios;

(...)

Art. 84. Compete privativamente ao Presidente da República:

$(\ldots)$

VIII - celebrar tratados, convenções e atos internacionais, sujeitos a referendo do Congresso Nacional;"

2.4.1 A terminologia e a questão referente à competência privativa do Senado Federal, objeto do art. 52, V, em face da competência exclusiva do Congresso Nacional prevista no art. 49, I.

O Dr. Saulo José Casali BAHIA, Professor de Direito Internacional da Universidade Federal da Bahia, ao tratar sobre o assunto em questão, aponta erronia contida nos arts. 49, I, 84, VIII, da mesma Carta. Diz ele que ambos os dispositivos cuidam conjuntamente de gênero e espécie, dado que tratado é gênero do qual são espécies os acordos e as convenções, daí ser bastante a utilização apenas da primeira categoria (tratados). Outra questão levantada pelo Prof. CASALI diz respeito ao alcance da expressão “operações externas de natureza financeira”, objeto do art. 52, V, da C.F./88, que atribui, no caso, competência privativa ao Senado Federal, o que faria antever a desnecessidade de apreciação dessas operações pela Câmara dos Deputados (cf. BAHIA, 2000, p. 11-13). Conclui o Prof. Casali BAHIA (2000, p. 5) afirmando que a melhor solução seria "admitir a 
possibilidade da celebração das operações externas nos moldes preconizados no inciso V do art. 52 da Carta Magna (sem a oitiva da Câmara dos Deputados) somente nos casos em que as operações não extrapolem o âmbito financeiro”.

\subsubsection{A antinomia entre os arts. 49, I, e 84, VIII}

Para melhor compreensão da questão, é necessária a transcrição referente aos Projetos do $1^{\circ}$ e do $2^{\circ}$ turnos da Constituição de 1988 e da Comissão de Redação.

“Art. 58 - É da competência exclusiva do Congresso Nacional:

I - aprovar, ou não, tratados e acordos internacionais ou atos que acarretem encargos ou compromissos gravosos ao patrimônio nacional;”

$2^{\circ}$ Turno do Projeto de Constituição

“Art. 50 - É da competência exclusiva do Congresso Nacional:

I - resolver definitivamente sobre tratados e acordos internacionais ou atos que acarretem encargos ou compromissos gravosos ao patrimônio nacional;”

Comissão de Redação

“Art. 49 - É da competência exclusiva do Congresso Nacional:

I - resolver definitivamente sobre tratados, acordos ou atos internacionais que acarretem encargos ou compromissos gravosos ao patrimônio nacional;”

Sobre o assunto, o Dr. Cachapuz de MEDEIROS, com maestria desenvolve o tema, relatando, pormenorizadamente, um histórico das deliberações da Assembléia Constituinte de 1987-1988. Destaca-se, pois, que, “ao trocar no texto a posição do qualificativo internacionais de tratados e acordos para atos, a Comissão de Redação alterou completamente o art. 49, inciso I. A redação passou a dar a entender que a competência do Congresso é restrita à aprovação dos tratados que acarretem encargos ou compromissos gravosos ao patrimônio nacional, pois ao não falar em atos apenas, mas em atos internacionais, equiparou-os aos tratados e acordos. Na prática brasileira, ato internacional é o mesmo que acordo internacional” (1995, p. 394), sendo ainda certo que o art. 84, VIII, confere ao Presidente da República competência privativa para celebrar tratados, convenções e atos internacionais, mas exige que todos sejam submetidos ao referendo do Congresso Nacional. 
2.4.3 A prática brasileira na celebração de tratados sob o regime da Constituição Federal de 1988.

Discorrendo sobre a prática do Congresso Nacional no exercício do controle dos atos internacionais, sob o pálio da Constituição de 1988, constata o Prof. Cachapuz de MEDEIROS (cf. MEDEIROS, 1995, p. 409-450) o seguinte:

a) a continuação de celebração de acordos sob a forma simplificada pelo Poder Executivo; para tanto, em acurada pesquisa, é noticiado que, de 05.10.1988 a 31.12.1993, o Congresso Nacional apreciou 185 tratados internacionais submetidos pelo Presidente da República. No mesmo período, o Governo celebrou 182 acordos sob a forma simplificada (pesquisa efetuada no Diário Oficial da União), entre os quais podem ser destacados os Acordos entre o Brasil e a Grã-Bretanha sobre Entorpecentes (1988), Brasil e Bolívia sobre de Integração Energética (1989), Brasil e Argentina sobre Transporte Rodoviário (1990), etc;

b) a inclusão de preceitos nos Decretos Legislativos, exigindo a aprovação de ajustes complementares pelo Congresso Nacional, ainda é motivo de discussão entre os parlamentares e preocupação do Itamaraty. Sobre o tema, reporta-se o Prof. Cachapuz de MEDEIROS (cf. MEDEIROS, 1995, p. 427-431) à posição exteriorizada pela Consultoria Jurídica do Ministério das Relações Exteriores, da lavra do Consultor Cançado TRINDADE (cf. TRINDADE, 1985, p. 5), no sentido de que devem ser submetidos ao Parlamento somente os ajustes complementares que resultem em revisão ou modificação de acordo já aprovado pelo Legislativo, o que pode ser exemplificado com o Decreto Legislativo $\mathrm{n}^{0}$ 97, de 1985, que referendou o texto da Convenção de Viena sobre Responsabilidade Civil por Danos Nucleares de 1963;

c) a possibilidade de o Congresso criar reservas ou apresentar emendas aos tratados também é matéria de debate no Legislativo e na doutrina. Apenas a título exemplificativo (cf. MEDEIROS, 1995, p. 447), citemos a aprovação parcial da Convenção 160 da O.I.T. pelo Decreto Legislativo $n^{0}$ 51, de 25.8.89, bem como a aprovação com emendas do Acordo de Comércio e Pagamentos entre o Brasil e a antiga Tchecoslováquia, firmado em 24.6.1960 (Decreto Legislativo $n^{\circ}$ 17, de 15.12.1961). 


\section{JURISPRUDÊNCIA RECENTE DO SUPREMO TRIB UNAL FEDERAL}

O tema objeto do presente trabalho também não pode prescindir, ainda que de forma bastante sintética, do entendimento jurisprudencial recente do Supremo Tribunal Federal.

\subsection{A PARIDADE NORMATIVA ENTRE ATOS INTERNACIONAIS E NORMAS INFRACONSTITUCIONAIS}

Abrindo o debate, afirma-se, pelo menos até a presente data, que o Supremo Tribunal Federal tem mantido o entendimento de que os tratados, uma vez recepcionados, têm status de lei ordinária (cf. VELLOSO, 2002, p. 5-25). Isto ficou evidente quando do julgamento da Ação Direta de Inconstitucionalidade $n^{0} 1.480-3 / D F$, que teve por objeto a Convenção $n^{\circ} 158$ da O.I.T. O eminente Relator, Ministro Celso de MELLO, elucida referido posicionamento ao afirmar que "os tratados ou convenções internacionais, uma vez regularmente incorporados ao direito interno, situam-se, no sistema jurídico brasileiro, nos mesmos planos de validade, de eficácia e de autoridade em que se posicionam as leis ordinárias, havendo, em conseqüência, entre estas e os atos de direito internacional público, mera relação de paridade normativa”. No mesmo sentido, o eminente Ministro Carlos VELLOSO, em recente trabalho doutrinário (2003, p. 20), esclarece o seguinte: “a) na

jurisprudência do Supremo Tribunal Federal, há paridade entre a norma brasileira de produção doméstica e a norma brasileira de produção internacional. Assim, o conflito entre uma e outra resolve-se, de regra, pelo mecanismo tradicional: lex posterior derogat legi priori. Todavia, há de se ter presente que a lei posterior não revoga o tratado anterior, mas simplesmente afasta, enquanto em vigor, as normas do tratado com ela incompatíveis. Assim, revogada a lei que afastou a sua aplicação, voltará o tratado a ter aplicação; b) em matéria tributária, entretanto, observa-se o princípio contido no artigo 98 do Código Tributário Nacional: o primado da norma brasileira de produção internacional” 


\subsection{O PACTO DE SÃO JOSÉ DA COSTA RICA}

O Supremo Tribunal Federal, pelo seu Plenário, ao julgar o HC 72.131/RJ firmou o entendimento de que, em face da Carta Magna de 1988, conforme noticiou o Ministro MOREIRA ALVES ao julgar o HC 75.306/RJ, "persiste a constitucionalidade da prisão civil do depositário infiel em se tratando de alienação fiduciária, bem como que o Pacto de São José de Costa Rica, além de não poder contrapor-se à permissão do artigo 5º, LXVII, da mesma Constituição, derrogou, por ser norma infraconstitucional geral, as normas infraconstitucionais especiais sobre prisão civil do depositário infiel” (apud AMARAL JÚNIOR, 2000, p. 8), vale dizer, o Supremo Tribunal Federal decidiu no sentido de que o art. $4^{\circ}$ do Decreto-lei no 911/69, que equipara o devedor-fiduciante ao depositário infiel, foi recepcionado pela Constituição Federal de 1988. Em síntese: consoante jurisprudência do S.T.F., há prevalência da norma constitucional (art. 5º LXVII) sobre disposição contrária do Pacto (art. $7^{\circ}, \mathrm{n}^{\circ} 7$ ), que limitou a prisão por dívida somente à hipótese de inadimplemento de obrigação alimentícia. Por sua vez, o Ministro Carlos VELLOSO (2003, p. 10) sustenta que "no caso de tratar-se de direito e garantia decorrente de Tratado firmado pelo Brasil, a incorporação desse direito e garantia, ao direito interno, dá-se com status constitucional, assim com primazia sobre o direito comum. É o que deflui, claramente, do disposto no mencionado $\S 2^{\circ}$ do art. $5^{\circ}$ da Constituição da República. O Supremo Tribunal Federal, todavia, não acolheu essa tese.”

\section{CONCLUSÕES}

É indubitável que a democratização do exercício do poder político, bem como a necessidade de coexistência e cooperação com os demais membros da sociedade internacional alteraram os protagonistas das relações jurídicas internacionais, vale dizer, os Soberanos, pessoas de Direito Internacional e, portanto, sujeitos capazes de celebrar tratados, foram substituídos pelos povos, estes constituídos em Estados juridicamente organizados, sendo certo que os Estados, no cenário internacional, agem em nome do povo: elemento basilar democrático. 
A constitucionalização, por sua vez, do exercício do poder político, aqui incluída a ação externa do Estado mediante a adoção de princípios de relações exteriores, distingue o processo de celebração de tratados, de forte predominância do Poder Executivo, do controle das ações governamentais pelo Poder Legislativo, o que é bastante salutar, dado que se ressalta a idéia de nação e de soberania nacional.

A história constitucional brasileira, mormente a republicana, consoante demonstrou o Prof. Cachapuz de MEDEIROS em sua obra (cf. MEDEIROS, 1995), acentua a submissão dos tratados ao referendo do Congresso Nacional, o que indubitavelmente fortalece o regime democrático mediante o controle político da ação externa do Estado pelo Poder Legislativo.

\section{REFERÊNCIAS}

ACCIOLY, Hildebrando. A ratificação e a promulgação dos tratados em face da constituição federal brasileira. Boletim da Sociedade Brasileira de Direito Internacional, Rio de Janeiro, n. 7, p. 11-15, jan./jun. 1948.

AMARAL JÚNIOR, José Levi Mello do. Os tratados no ordenamento jurídico brasileiro. Revista Jurídica Virtual, n. 11, p. 8, abr./2000. Disponível em: http:// www.presidencia.gov.br/ccvil_03/revista/ Rev_11/os_tratados.htm. Acesso em: 13 jun. 2003.

ARAÚJO, João Hermes Pereira de. A processualística dos atos internacionais. Rio de Janeiro: Ministério das Relações Exteriores, 1958.

BAHIA, Saulo José Casali. Tratados internacionais no direito brasileiro. Rio de Janeiro: Forense, 2000.

BROTONS, Antonio Remiro. La acción exterior del estado. Madrid: Technos, 1984.

CARNEIRO, Levi. Acordos por trocas de notas e aprovação pelo congresso nacional. Boletim da Sociedade Brasileira de Direito Internacional, Rio de Janeiro, n. 13, p. 14129, 
jan./dez. 1951.

DALLARI, Pedro. Constituição e relações exteriores. São Paulo: Saraiva, 1994.

FRANCO, Afonso Arinos de Melo. Estudos de direito constitucional. Rio de Janeiro:

Forense, 1957.

LAFER, Celso. Parodoxos e possibilidades. Rio de Janeiro: Nova Fronteira, 1982.

Diplomacia e transparência: o arquivo do Itamarati. Acervo - Revista do Arquivo Nacional, Brasília, v. 4, n. 2, p. 3646, jul./dez. 1989.

MEDEIROS, Antônio Paulo Cachapuz de.

O poder de celebrar tratados: competência dos poderes constituídos para a celebração de tratados, à luz do direito internacional, do direito comparado e do direito constitucional brasileiro. Porto Alegre: Sérgio Antônio Fabris Editor, 1995.

REZEK, José Francisco. As relações internacionais na constituição da primeira república. Arquivos do Ministério da Justiça, Brasília, n. 126, p. 110-111, jun. 1973.

Direito dos tratados. Rio de Janeiro: Forense, 1984.

SOARES, Guido Fernando da Silva. Acordos administrativos e sua validade no Brasil. Revista da Faculdade de Direito (Universidade de São Paulo), São Paulo, n. 72 (2), p. 322, 1977.

SUPREMO TRIBUNAL FEDERAL, Plenário, ADI 1.480-Ml/DF, Relator: Ministro Celso de Mello, Data do julgamento: 04.9.97, DJ de 18.5.2001.

SUPREMO TRIBUNAL FEDERAL, Plenário, HC 72.131/RJ, Relator para o acórdão: Ministro Moreira Alves, Data do julgamento: 23.11.95, DJ de $1^{\circ} .8 .2003$. 
SUPREMO TRIBUNAL FEDERAL, Primeira Turma, HC 75.306/RJ, Relator: Ministro Moreira Alves, Data do julgamento: 19.8.97, DJ de 12.9.97.

TRINDADE, Antonio Augusto Cançado. A Questão da Aprovação pelo Legislativo de Atos Internacionais. Informação CJ/05 do Consultor Jurídico do Ministério das Relações Exteriores para o Senhor Ministro de Estado, de 21 de outubro de 1985, p. 5.

VALLADÃO, Haroldo. Aprovação de ajustes internacionais pelo congresso nacional. Boletim da Sociedade Brasileira de Direito Internacional, Rio de Janeiro, n. 11, p. 1295, jan./dez. 1950.

VELLOSO, Carlos Mário da Silva. O direito internacional e o Supremo Tribunal Federal. Revista de Direito Administrativo, Rio de Janeiro, n. 229, p. 5-25, jul./set. 2002. - Tratados internacionais na jurisprudência do Supremo Tribunal Federal. SEMINÁRIO O DIREITO NA ERA DA GLOBALIZAÇÃO: TRATADOS INTERNACIONAIS NA ORDEM JURÍ-DICA. Palestra, 12.5.2003, São Paulo, Universidade Presbiteriana Mackenzie, Comissão de Relações Internacionais do Conselho Federal da Ordem dos Advogados do Brasil e Harvard Law School Association do Brasil. 